\title{
Potencialidades de uma etnografia das ruas do passado
}

\author{
Fraya Frehse
}

resumo Trata-se aqui de refletir sobre o rendimento da etnografia para o estudo antropológico de temáticas históricas recorrendo às balizas teórico-metodológicas que nortearam a pesquisa de que resultou minha tese de doutorado (Frehse 2004). Buscarei, à luz delas, explorar especificamente as potencialidades de uma etnografia das ruas centrais de Sáo Paulo entre o início do século XIX e o início do XX. No intuito de trazer à tona essas potencialidades, a reflexão se estrutura em duas etapas. Primeiramente, cabe construir teoricamente o argumento de que a etnografia pode perpassar também estudos antropológicos referentes a temáticas históricas por ser perpassada por uma perspectiva epistemológica muito específica: a perspectiva etnográfica. Com o objetivo de provar a pertinência do argumento, submeterei meu próprio estudo de doutorado a um estranhamento a posteriori, a fim de avaliar nele a presença do recurso à etnografia. Será então possível destacar que a perspectiva etnográfica carrega consigo, para o estudo antropológico das ruas paulistanas do passado oitocentista, potencialidades que são de cunho teórico-metodológico e literário, a despeito das inevitáveis limitaçôes da etnografia para o trato de temáticas históricas.

palavras-chave Antropologia histórica. Etnografia. Epistemologia. Perspectiva etnográfica. Etnografia e vida cotidiana.

Tendo me dedicado durante a minha pósgraduação em Antropologia Social à reflexão antropológica a respeito de temáticas históricas (Frehse 1999, 2004 e 2005a), gostaria, neste texto, reformulado especialmente para integrar esta edição comemorativa da revista Cadernos de Campo , de refletir sobre o rendimento da etnografia para o estudo antropológico de temáticas históricas. Considerando-se que esse tipo de investigação depende fortemente da análise de documentos históricos, quais as potencialidades da etnografia para esse tipo de pesquisa no âmbito da antropologia?

O objetivo de enfrentar essa questão inspirou a elaboração deste artigo. Para fazê-lo nos limites do presente texto, discutirei a problemática a partir das balizas teórico-metodológicas que nortearam a pesquisa de que resultou a minha tese de doutorado (Frehse 2004). Buscarei, à luz delas, explorar especificamente as potencialidades de uma etnografia das ruas centrais de São Paulo entre o início do século XIX e o início do XX. Foi este o cenário espaço-temporal de referência para a apreensão de transformações nas regras de comportamento corporal e de sociabilidade na cidade então; transformações essas que me interessaram por aquilo que poderiam revelar a respeito da maneira como a sociedade paulistana da época se ajustou, em termos culturais, à possibilidade histórica da modernidade no momento mesmo em que esta foi começando a fazer-se presente em Sáo Paulo, em meio à crescente prosperidade das exportaçóes cafeeiras

1. Versão reformulada da comunicação apresentada no Simpósio "Sociedade, población y economia" do VI Congreso Internacional de Etnohistoria realizado em Buenos Aires (Argentina) entre 22 e 25 de novembro de 2005. 
do interior da província e à decadência da escravidão no país.

No intuito de trazer à tona essas potencialidades, é necessário antes demonstrar por que a etnografia pode perpassar também estudos antropológicos referentes a temáticas históricas. Essa é uma etapa relevante para a reflexão, dada a associação quase imediata que, desde a famosa introdução de Argonautas do Pacifico Ocidental, costuma ser feita, na disciplina, entre etnografia e uma metodologia baseada no uso da chamada "observaçáo participante" durante o chamado "trabalho de campo". O estudo de temáticas históricas evidentemente vai na contramão de tais preceitos: é impossível fazer "observação participante", e o "campo" é o arquivo. Há como, nesse contexto, falar em etnografia?

A meu ver, sim, já que esta é perpassada por uma perspectiva epistemológica muito específica: aquilo que chamarei de perspectiva etnográfi$c a$. Com o objetivo de provar a pertinência do argumento, submeterei o meu próprio estudo de doutorado a um estranhamento a posteriori, a fim de avaliar nele a presença do recurso à etnografia. Será entáo possível destacar que a perspectiva etnográfica carrega consigo potencialidades de cunho teórico-metodológico e literário para o estudo antropológico das ruas paulistanas do passado oitocentista, a despeito das inevitáveis limitaçóes que a etnografia apresenta para o trato de temáticas históricas.

\section{A etnografia como perspectiva episte- mológica}

Se a antropologia se particulariza por, como assinala Eduardo Viveiros de Castro ([1998] 2002), "dialogar para valer", num mesmo "plano epistemológico", com aqueles que são objeto do discurso antropológico, o que caracteriza tal empreendimento como "antropológico" quando o que se pretende é analisar práticas cultu- rais vigentes em um contexto espaço-temporal que não é de forma alguma aquele em que vive o pesquisador que sobre elas se debruça?

No meu modo de ver, a característica distintiva é que, mesmo quando o arquivo é o "campo" no qual transcorre a pesquisa empírica, esta permanece orientada, em termos epistemológicos, pela ênfase num modo de conhecer que é propriamente etnográfico, quando o pesquisador recorre a sua formação antropológica para analisar o contexto espaço-temporal em questáo. A etnografia envolve uma determinada perspectiva de conhecimento da vida social que leva o antropólogo a, no contato com material histórico, atentar para aspectos que os colegas historiadores, em contato com a mesma documentação, deixam em segundo plano em favor de outros dos quais o antropólogo, por sua vez, passa ao largo. De que perspectiva se trata?

A fim de encontrar uma resposta há que se contemplar, mesmo que brevemente, o debate a respeito das características da etnografia como recurso célebre da antropologia no mínimo desde os estudos pioneiros de Malinowski. Para este autor, "etnografia” é o rótulo de uma ciência ([1922]1978: 18). Outros antropólogos evocam a noção para aludir à experiência cognitiva de cunho existencial forjada no estranhamento das distâncias e proximidades entre as referências (culturais e teóricas) do pesquisador e aquelas dos "outros" que ele estuda (cf., por exemplo, as notórias consideraçóes de Lévi-Strauss [1958]1970: 16 e de Geertz [1973]2000: 6, mas também de Lévi-Strauss [1960]1973: 16 e de Geertz 1988, desenvolvidas, no cenário acadêmico nacional, por Peirano 1995 e Goldman 2001). Em diálogo com essas concepçóes todas, há quem argumente especificamente que "etnografia” rotularia um "método" específico da antropologia para estudar grupos humanos (Magnani 2002: 17).

Paralelamente a essas reflexóes metodológicas, consolidaram-se, sobretudo a partir da 
década de 1980, outras, mais fortemente referidas ao papel político-social da etnografia. $\mathrm{O}$ historiador da antropologia James Clifford foi pioneiro em conceber a etnografia essencialmente como uma negociação política que marca o contato entre antropólogo e nativos durante a pesquisa de campo e a formalização textual da interpretaçáo dos resultados da investigação ([1983]2002: 43). Dialogando com essa visão, ganharam espaço outras que visavam enfatizar, por meio do termo, uma forma específica de representação textual da análise antropológica (cf., por exemplo, Marcus e Cushman 1982; Clifford e Marcus 1986; Geertz 1988).

Em meio a essa plêiade de pontos de vista, interessam-me particularmente as referências à experiência cognitiva implícita à etnografia. Esse tipo de ênfase se faz presente num debate amplo que, vigente não apenas no cenário acadêmico internacional, mas nacional atualmente, fornece esclarecedoras argumentaçóes em relação ao fato de que a etnografia de forma alguma se restringe ao contato tête- $a$-tête com os nativos: o "campo" do trabalho de campo antropológico pode ser também o arquivo ${ }^{2}$. Cecília McCallum,

2. No contexto internacional a discussão já é mais antiga (Bloch 1977; Geertz [1980]1991; Sahlins 1981; Gaunt 1982; Rowland 1987). No que se refere ao cenário brasileiro, discussões sistemáticas sobre a temática são mais recentes e vêm tendo lugar em eventos científicos específicos. Sobressai nesse sentido, entre outros, o Seminário Temático "A Antropologia e seus métodos: o arquivo, o campo, os problemas", coordenado por Marcio Goldman e Emerson Giumbelli e realizado no âmbito do $25^{\circ}$ Encontro Anual da ANPOCS, de outubro de 2001 e cujas contribuiçóes estão registradas em disquete (Seminário 2001), e o Seminário "Quando o campo é o arquivo: etnografias, histórias e outras memórias guardadas", coordenado por Celso Castro e Olívia Maria Gomes da Cunha realizado pelo CPDOC da Fundação Getulio Vargas e pelo Laboratório de Antropologia e História do IFCS/UFRJ em novembro de 2004, e cujas contribuiçôes foram publicadas na revista Estudos Históricos, 36, 2005. em particular, reconhece na etnografia a "postura epistemológica que define a antropologia" (McCallum 2001: 6). E isso porque os dados na pesquisa antropológica constituiriam um "fato social total": a etnografia fundamenta-se num duplo "processo de objetivação" do etnógrafo, que aprecia os processos de "objetivação" vividos pelos outros que estuda para, num segundo momento, "auto-objetivar-se" por meio da análise e da descrição que faz do contexto apreendido (Idem: 8-9). Argumentando nesses termos, a autora acaba por trazer para o primeiro plano que à etnografia, táo decisiva para um conhecimento de cunho antropológico, está implícito um modo de conhecer a realidade sociocultural. É uma "postura" perante o conhecimento, uma maneira de justamente posicionar-se perante o contexto de estudo durante e após o trabalho de campo, nas etapas de análise e de interpretação dos dados.

Essa é a associação mais explícita que pude encontrar entre etnografia e epistemologia. Importa, para os fins deste texto, que ela abre espaço para uma concepçáo alternativa de etnografia, mais "liberta", por assim dizer, da associação automática com o trabalho de campo baseado no contato físico, tête-à-tête, com os sujeitos a serem estudados. $\mathrm{E}$ isso por mais que McCallum tenha, ela mesma, realizado trabalho de campo para a abordagem de antropologia da saúde que apresenta em seu estudo (2001).

Ancorada nessa argumentação, gostaria de, parodiando o provérbio, "aumentar um ponto" desse "conto". Ou diminuir, considerando-se que parto de uma dimensão epistemológica específica embutida na noção de "objetivação dupla”. No meu modo de ver, esta ocorre também quando o contato com os processos de objetivação dos “outros" e do próprio antropólogo é mediado particularmente por documentos históricos. McCallum preconiza a existência da dupla objetivação inspirada nas consideraçóes 
de Lévi-Strauss ([1950]1997) sobre a noção maussiana de "fato social total". Menos do que recuperá-las aqui, importa enfatizar que há embutida nelas a proposição de um modo específico de conhecer a vida social. E é justamente esse modo de conhecer que é ensinado ao estudante de antropologia quando este toma contato com a noção de etnografia. Aprender a "fazer etnografia" é aprender, antes de tudo, a impregnar corpo e alma, inteligência e sensibilidade da imprescindibilidade da busca pelo "diálogo para valer". E isso, mesmo sabendo que o conhecimento antropológico é sempre menos do que aquilo que o outro diz e sempre mais do que aquilo que se poderia dizer sem o outro. Ora, precisamente esse fundamento epistemológico da etnografia abre espaço para que se a reconheça ativa em relação aos mais diversos "campos" de estudo, quando o pesquisador se propóe uma pesquisa antropológica. A consciência da necessidade do "diálogo para valer" é o ponto para o qual convergem as impressóes coletadas mais ou menos aleatoriamente em campo, seja quando o campo é o campo tradicional do trabalho antropológico, seja quando é o arquivo. É por serem submetidos a essa consciência que os dados coletados pelo antropólogo via contato direto ou indireto com os sujeitos estudados se transformam em dados propriamente etnográficos.

No intuito de ressaltar essa dimensão do vínculo entre etnografia e epistemologia, privilegio relacionar etnografia a uma perspectiva epistemológica. Aquilo que chamo de perspectiva etnográfica é forjada na metáfora da perspectiva para destacar, na concepção de etnografia, a sua dimensáo de ponto de fuga para o qual converge a maneira de o pesquisador apreender, analisar, interpretar, representar e, assim, conhecer a vida social, independentemente de sua forma de contato com o seu "campo" empírico de estudo.

Trata-se, por isso mesmo, de um modo de conhecer a realidade que impregna todas as etapas metodológicas envolvidas na realizaçáo de uma pesquisa antropológica. Perpassa a formulação da questão teórica, a definição do objeto, do cenário espaço-temporal empírico de referência; envolve a construção da referência metodológica, o levantamento, a sistematização e análise dos dados e a redação do texto monográfico.

Com o propósito de demonstrar a pertinência do argumento, trata-se agora de rastrear a presença a perspectiva etnográfica numa investigação antropológica na qual o tempo histórico de referência é o passado. Cabe debruçar-se sobre as minhas opçóes teóricas, metodológicas e literárias na investigação que originou a tese de doutorado (Frehse 2004). E isso para demonstrar como os procedimentos metodológicos da investigação estão impregnados da perspectiva etnográfica.

\section{Em busca da perspectiva etnográfica}

O exercício de estranhamento que viso aqui realizar pressupóe que a perspectiva etnográfica medeia os procedimentos metodológicos, não os determina mecanicamente. Nunca é demais relembrar Malinowski: "Não é suficiente [...] que o etnógrafo coloque suas redes no local certo e fique à espera de que a caça caia nelas. [...] $\mathrm{O}$ pesquisador de campo depende inteiramente da inspiraçáo que lhe oferecem os estudos teóricos” ([1922] 1978: 22-23). Desde então, quando o assunto é etnografia, é freqüentemente reiterada, mesmo que a partir de abordagens teóricas distintas, a premissa de que o conhecimento etnográfico depende de uma boa formação teórica prévia (cf., por exemplo, DaMatta [1974]1978: 24; Geertz [1983]2000: 55-70; Peirano 1995: 44-45; 2006: passim). Tais consideraçóes sugerem que a etnografia não indica mecanicamente o que conhecer. Ela intermedeia a relação do pesquisador com aquilo que quer conhecer com base em determinada formação 
teórica. E a questáo se torna saber como essa mediação se faz presente na definição da questão teórica do estudo, na definição do objeto, na construção de referências metodológicas, no levantamento, sistematização e análise dos dados, na redação da monografia.

A questão teórica que enfrentei em minha pesquisa de doutorado foi a seguinte: como a sociedade paulistana oitocentista, rural e de fortes raízes estamentais e escravistas, se ajustou, em termos culturais, ao advento da modernidade em seu dia-a-dia na cidade (Frehse 2004: 7)? De fato, o momento é de difusão ali, em intensidade até então inédita, da realidade social e cultural ligada à concepção de que tudo e todos são transitórios, moda, modernos - com todas as contradiçóes que essa realidade envolve e acarreta. É um processo histórico que começa a fazer-se presente no dia-a-dia dos indivíduos em São Paulo; em particular, com a prosperidade crescente das exportaçóes cafeeiras e a decadência da escravidáo no país, a partir da segunda metade do século XIX.

Ajuste cultural certamente não significa abdicar das próprias referências em favor de outras quaisquer. É verdade que, como bem discerniu Marshall Sahlins ([1985]1994: 181-87) a partir de um diálogo com categorias de Marx, os indivíduos colocam, na ação - "práxis" -, as suas categorias "em relaçóes ostensivas com o mundo". Os significados dos objetos são, na práxis, submetidos a riscos objetivos (acasos) e a riscos subjetivos (as intençóes desses mesmos indivíduos e a relaçáo dos signos com outros, no interior do sistema de relaçôes entre signos que define a cultura). É por isso que o autor afirma que a cultura é ordenada historicamente. Todavia, ao mesmo tempo Sahlins argumenta, parafraseando Franz Boas, que "o olho que vê é o olho da tradição", por causa da capacidade humana de atribuir significados aos fenômenos. Justamente por conceber a "ação simbólica” em termos dialéticos é que o antro- pólogo recupera, especificamente para o debate sobre a noção de cultura, toda a potencialidade da noção de práxis que, já presente em Marx, foi tão bem desenvolvida pelo sociólogo Henri Lefebvre (1966: 43) na distinção que este fez entre os três níveis da práxis, ou seja, do "ato; relação dialética entre a natureza e o homem, as coisas e a consciência”. Este autor diferenciou entre práxis repetitiva (que "recomeça os mesmos gestos, os mesmos atos em ciclos determinados"), práxis mimética (que "segue modelos", criando sem saber como nem por quê) e práxis inventiva e criadora (que "introduz descontinuidades no processo global sócio-histórico"). $\mathrm{O}$ ajuste que me interessou na investigação aqui perscrutada se dá justamente nesse meio de caminho entre a irreversibilidade da mudança e a originalidade cultural em relação a esta mesma mudança. É um meio de caminho cheio de reinvenções, marcado que é pela ressignificação sempre inconclusa do velho como novo e vice-versa.

Abordei a temática teórica do ajuste cultural à modernidade a partir de interlocuçáo com autores que se preocupam, cada um à sua maneira, em abrir espaço para um aprofundamento teórico-metodológico da práxis marxiana. Por sua vez, esta noção remete instantaneamente à análise dos fatos sociais no plano da vida de todo dia dos indivíduos. Ora, não é para essa seara da vida social que a etnografia enquanto perspectiva epistemológica instiga o antropólogo? Ao sinalizar para a busca epistemológica incessante do "diálogo para valer", a perspectiva etnográfica estimula o pesquisador justamente a atentar para os pequenos fatos do dia-a-dia, para o aparentemente insignificante que está além - ou aquém - das previsôes oficiais e dominantes. É essa a natureza dos dados que marca aquilo que Malinowski chamou de "carne e sangue da vida nativa". Em passagem célebre, escreveu o antropólogo polonês sobre os chamados "imponderáveis da vida real": 
Pertencem a essa classe de fenômenos: a rotina do trabalho diário do nativo; os detalhes de seus cuidados corporais; o modo como prepara a comida e se alimenta; o tom das conversas e da vida social ao redor das fogueiras; a existência de hostilidade ou de fortes laços de amizade, as simpatias ou aversóes momentâneas entre as pessoas; a maneira sutil, porém inconfundível, como a vaidade e a ambiçáo pessoal se refletem no comportamento de um indivíduo e nas reaçóes emocionais daqueles que o cercam ([1922]1978: 29).

Como, no meu caso, o assunto era o advento da modernidade em Sáo Paulo no século XIX, era claro para mim que esses "imponderáveis" não poderiam ser apreendidos sem levar em conta o processo histórico mais abrangente de difusão de um modo de vida muito específico, cotidiano, na vida de todo dia dos indivíduos na cidade. Adveio daí a interlocução intensa com a sociologia de Lefebvre - novamente (tendo-se em mente que já a iniciara no mestrado - cf. nesse sentido Frehse 1999 e 2005a). Com o objetivo de aprofundar a compreensão dos dilemas sócio-históricos do ajuste cultural que perpassam a práxis dos indivíduos, uma referência relevante para a reflexão é a abordagem sahlinsiana sobre as ressignificaçôes culturalmente específicas de fatos históricos. E dá-lhe Sahlins - também novamente (considerando que também no mestrado suas reflexóes foram relevantes para a abordagem antropológica de outra temática histórica).

A atenção etnográfica à vida cotidiana acabou sendo relevante também para a operacionalização da questão teórica e conseqüente definição do objeto de estudo. Para uma compreensão antropológica desses ajustes culturais no plano da vida de todo dia dos indivíduos na Sáo Paulo oitocentista, foi fundamental que o objeto de estudo favorecesse a apreensão analítica da dinâmica cultural relativa à práxis desses mesmos indivíduos em sua rotina na cidade de então. Essa orientação epistemológica me impulsionou a um aprofundamento nas abordagens sociológicas da vida cotidiana no mundo contemporâneo, seja em sua vertente microssociológica (cf., por exemplo, Schütz [1970]1979; Goffman [1959]1995; 1967; Garfinkel [1967]1984), seja em sua visada histórico-dialética (cf. em especial Lefebvre 1958, 1961, [1968]1972, 1981)3. Tive entáo como incorporar como orientação metodológica, por um lado, que o plano da vida social cuja análise é favorecida pela perspectiva etnográfica é atravessado por especificidades sócio-históricas. No contexto paulistano em foco, a vida de todo dia se encontrava mais e mais influenciada pelo modo de vida "cotidiano", que se define pelo fato de que os ritmos temporais e espaciais tributários da racionalidade capitalista interferem de forma crescente na vida de todo dia dos sujeitos a serem estudados; e isso, seja porque esses ritmos representam ameaças inexoráveis, seja por terem se transformado em regras de conduta dominantes, seja por serem forças às quais resistir com unhas e dentes. Por outro lado, analisar as práticas culturais no plano da vida de todo dia implica considerar também as variáveis situacionais que as envolvem.

Aliar a perspectiva epistemológica da etnografia à orientação metodológica de foco sobre as práticas culturais da vida de todo dia em suas peculiaridades microssociológicas e sócio-históricas conduziu-me a privilegiar como objeto de análise as transformaçóes nas regras de conduta referentes aos comportamentos corporais e às interaçóes sociais no espaço urbano paulistano oitocentista. $\mathrm{O}$ objetivo específico passou a ser atentar para como se modificaram as regras de conduta no intuito de averiguar o que elas poderiam revelar sobre a maneira como a socieda-

3. Uma revisão bibliográfica crítica dessas e de outras referências encontra-se em José de Souza Martins ([1998]2000: 55-64). 
de pode ter se ajustado na cidade à difusão da modernidade.

Mas por que as regras de conduta revelariam algo sobre o ajuste? Elas medeiam, como sugere Erving Goffman, comportamentos e interaçóes ([1956]1967). O que envolve tanto a seara da cultura - se temos em mente que regras são sempre de cunho simbólico - quanto a da moral, já que as regras envolvem um grupo de adeptos, sendo que é a adesão às regras que leva à constância e padronização dos comportamentos. Essa dupla perspectiva permite ir ao encontro de uma terceira: a da história da civilidade nos termos em que a noção foi como trabalhada pelo historiador Jacques Revel. Nos termos deste estudioso, a civilidade é linguagem corporal destinada às "exigências do comércio social", quer se trate de membros do próprio grupo ou de outros ainda ([1986]1991:169).

Civilidade é uma categoria êmica da sociedade ocidental européia (Pons 1992:21), sendo que o seu sentido histórico primeiro se liga às regras corporais socialmente desejáveis para a convivência na cidade enquanto forma específica de povoamento humano (etimologicamente "civilidade" remete à conduta socialmente desejável, "civil", dos "cidadãos", moradores da "cidade"). Náo obstante, com a modernidade a noçáo começa a difundir-se pelo mundo afora a partir da França com um novo sentido. Corresponde a uma linguagem corporal que, propagada pela burguesia francesa em ascensão econômica e política, a partir do século XVIII, se propunha como adequada à "civilização" constituída a partir da hegemonia política e sociocultural dessa mesma burguesia (Elias [1939]1993). O termo passa a dizer respeito aos tempos "modernos" instaurados pela mediaçáo do poder dessa classe. Não é, nesse sentido, casual que tenha sido na Paris das revoluções liberais do século XIX que foi inventado por Baudelaire o neologismo "modernidade".
À luz dessas ponderaçôes, compreender como se alteram as regras de conduta em São Paulo em meio ao advento da modernidade ali significa apreender como a sociedade, tão marcada pela cultura caipira das plagas rurais e interioranas do sudeste da antiga colônia portuguesa na América, foi se ajustando aos padróes de civilidade implícitos a essa realidade social e cultural marcada pela concepçáo de que tudo e todos são transitórios.

Evidentemente, o objeto precisou ser recortado. Civilidade onde exatamente? Quando? De quem? Também esse procedimento metodológico foi encaminhado pela mediação da perspectiva etnográfica. As ruas paulistanas à luz do dia emergiram como cenário espaço-temporal privilegiado para o contato analítico com aquilo que Geertz chama de dimensão "pública" da cultura ([1973]2000: 12). Como proclama a literatura especializada na temática da modernidade nas grandes cidades oitocentistas (Frehse 2004: 14-17), a rua constitui ali o espaço que sintetiza as concepçóes de fugacidade e transitoriedade que caracterizam essa realidade social e cultural. Então, concentrar-se nas transformaçóes nas regras de conduta nesse cenário à luz do dia, que é quando ocorre com toda a intensidade a difusáo de objetos, relaçóes sociais e concepçóes historicamente próprias da modernidade em meio à movimentaçáo humana intensa que ali se dá, favorece a análise etnográfica do ajuste cultural à civilidade historicamente própria desse tipo de realidade. Com efeito, a regra de movimentação corporal nas ruas das grandes cidades modernas à luz do dia envolve um conjunto de técnicas corporais, usos físicos do corpo (Mauss [1936]1997: 365), que, exercitadas num ritmo específico, numa seqüência de repetiçóes indutoras de "maneiras" (Lefebvre 1992: 55), resultam num comportamento corporal definido: a circulação, passagem regular pelas ruas. Quanto às interaçóes, a regra que as perpassa é a impessoalidade, cedo problematizada, em termos teóricos, 
por Georg Simmel ([1903]1967: 14-18). E isso, quer os indivíduos se movimentem pela cidade isolados ou ajuntados em multidóes. A circulação impessoal como regra básica daquilo que chamei de civilidade moderna (Frehse 2004: 25) exprime assim, no plano dos movimentos corporais e dos contatos sociais diários, o princípio de transitoriedade que sintetiza a modernidade. Circulação: trânsito. Impessoalidade: atributo do transeunte. É a essas referências que os indivíduos tiveram de ajustar os seus corpos em seu dia-a-dia nas ruas de São Paulo, modificando de forma original as regras de civilidade historicamente antigas que até então tinham mediado os seus comportamentos corporais e interaçóes sociais nas ruas. $\mathrm{O}$ que pode revelar os termos do ajuste em questáo no plano "carne e sangue da vida nativa" - no caso, substanciado nos comportamentos corporais e nas interaçóes ${ }^{4}$. Esse plano é fundamental para o "diálogo para valer" com as práticas culturais paulistanas em processo de ajuste à difusão da modernidade, nos Oitocentos.

Definido esse recorte, a questão teórica pôde ser reposta, só que de maneira mais precisa. É que o contato com a historiografia paulistana referida à vida social nas ruas do início dos Oitocentos deixava entrever que ali a circulação e a impessoalidade não eram de forma alguma regras de conduta relevantes ali durante o dia. E muito menos à noite. As ruas, até mesmo as centrais, eram lugares em que os pobres, escravos, forros ou livres, se deixavam ficar dia a dia e pelas quais os senhores e suas famílias passavam apenas em ocasióes especiais, festivas, nem um pouco cotidianas. Ora, o que seria desse mundo em face da difusão da modernidade e suas regras de civilidade nas ruas, isto é, em face do irreversível ajuste ao moderno e a dife-

4. Aliás, Geertz preconiza que deveria ser o "comportamento" o foco primordial do antropólogo, "pois é através do fluxo do comportamento - ou, mais precisamente, da ação social - que as formas culturais encontram articulação" ([1973]2000: 17). renciação original em relação a este? Como a sociedade paulistana foi, nas ruas, se ajustando aos padróes da civilidade moderna ali?

A fim de responder a questão, permanecia necessária uma referência metodológica que me guiasse analiticamente pelas ruas paulistanas a serem perscrutadas através da documentação histórica. Que personagem me forneceria os seus "ombros" para que eu, por detrás deles, pudesse passear analiticamente pelas ruas do centro paulistano entre o início do século XIX e o início do XX em busca de um estranhamento etnográfico das regras de civilidade e suas mudanças ao longo do tempo?

Foi essa preocupação simultaneamente epistemológica e teórico-metodológica que trouxe para o primeiro plano a importância metodológica do transeunte para a minha investigação. É ele o protagonista mais acabado das regras de conduta que definem a civilidade moderna. Trata-se da personagem na qual qualquer indivíduo - homem, mulher ou criança - se transforma nos momentos mais ou menos fugidios em que pelas ruas passa entre um lugar e outro com regularidade. Na rua o transeunte corporifica a circulação como regra de conduta que envolve os comportamentos corporais dos indivíduos nesse espaço; e a impessoalidade como regra relativa à sociabilidade desses indivíduos ali.

Estabelecida a referência metodológica, abria-se espaço analítico para novas perguntas. Quem seriam os transeuntes nas ruas de São Paulo nos Oitocentos, cenário físico em que a diferença entre aqueles que serviam e aqueles que eram servidos se expressava também no tipo de movimentação física por ali? Quem transitaria por essas ruas dia a dia, se elas eram eminentemente lugares dos pobres, e se os indivíduos social e economicamente mais prestigiados as freqüentavam apenas em dia de missa ou de festa? E uma vez nas ruas, como interagiriam entre si os indivíduos? 
Em relação à São Paulo oitocentista, não faltam abordagens sobre o dia-a-dia de grupos sociais específicos. Mas pouco se sabia sobre uma outra dimensão da experiência que os membros de cada segmento vivenciaram separadamente, em suas movimentaçóes e interaçóes diárias nesse espaço: a relação de cada indivíduo (de qualquer que seja o grupo) com e em meio a terceiros variados nas ruas, indivíduos mais ou menos "estranhos", enquanto a modernidade ia se difundindo na cidade.

Retomar aqui essas ponderaçóes visa explicitar que também o papel metodológico do transeunte em minha investigação muito deve à perspectiva etnográfica. O que o transeunte revela sobre a maneira como a sociedade se ajustou ao advento da modernidade em Sáo Paulo? Tendo-se em mente que o transeunte corporifica as duas regras de conduta acima explicitadas, é em especial a primeira que permite entrever toda a potencialidade metodológica da personagem. Está em jogo na circulação um conjunto de técnicas corporais num ritmo específico: a passagem física pelas ruas regularmente. Já que os ritmos são constituídos por repetiçóes cíclicas (de origem cósmica) e lineares (de origem social) de movimentos no tempo que, precisamente por ocorrerem no espaço, engendram diferenças (Lefebvre 1992), eles constituem uma via privilegiada para a compreensão das mudanças sociais no "nível" do "vivido", do "carnal”, do "corpo" (Idem: 91). Uma vez que esse nível é caro ao "diálogo para valer" que o antropólogo busca, então o transeunte é, no contexto em foco, uma referência metodológica extremamente útil. Se tornar-se transeunte é inevitável na São Paulo oitocentista, a questão é apreender como a passagem regular, a circulação, vira regra de comportamento nas ruas; e o que tal fato implica para as regras de conduta que envolvem as interaçóes.

Permanece em aberto como procedi nessa direção, se só o que tinha à disposição eram do- cumentos históricos. Os ombros nativos ainda parecem táo distantes...

Também na etapa do levantamento de dados a perspectiva etnográfica se mostrou de valia. Se o que importava eram movimentos corporais e interaçóes dos indivíduos em seu dia-a-dia nas ruas da cidade ao longo do século XIX, seria necessário concentrar-se em fontes históricas que revelassem a dinâmica envolvida nesse plano "carnal" dos corpos em movimento pelas vias durante o dia, momento de maior burburinho humano ali, ao longo de todo o século. Fui assim conduzida a ruas específicas, a períodos históricos também definidos e, conseqüentemente, a documentos peculiares.

Levando-se em conta a importância da dimensão de "teatro espontâneo" que envolve a rua em qualquer cidade (Lefebvre 1970: 29), mas também as próprias características da história da urbanização paulistana, nota-se que um perímetro relativamente restrito de vias centrais no núcleo povoado da cidade congregava, nesse momento, as principais funçóes político-administrativas, comerciais, lúdico-religiosas e, a partir de finais dos Oitocentos, até funçōes industriais. É inevitável, portanto, que para ali fossem atraídos dia a dia, enquanto era dia, grupos sociais dos mais diversos, e que fosse grande a pressão social (e político-repressiva) em prol da civilidade moderna. Estou falando das ruas, becos, travessas e largos da chamada colina histórica que, para fins operacionais, recortei de maneira definida, que reproduzo para aproximar o leitor o máximo possível do cenário em relaçáo ao qual realizei a etnografia das ruas do passado (Figura 1).

Convém ressaltar que se remeter a esse cenário físico sob a orientaçáo da perspectiva etnográfica implicou incorporar à noção de "rua" todas as variaçóes topográfico-urbanísticas (largos, becos, praças, ladeiras) decorrentes do princípio básico que define a rua: o fato de ser lugar público, de acesso social irrestrito. Por 
308 FraYa Frehse

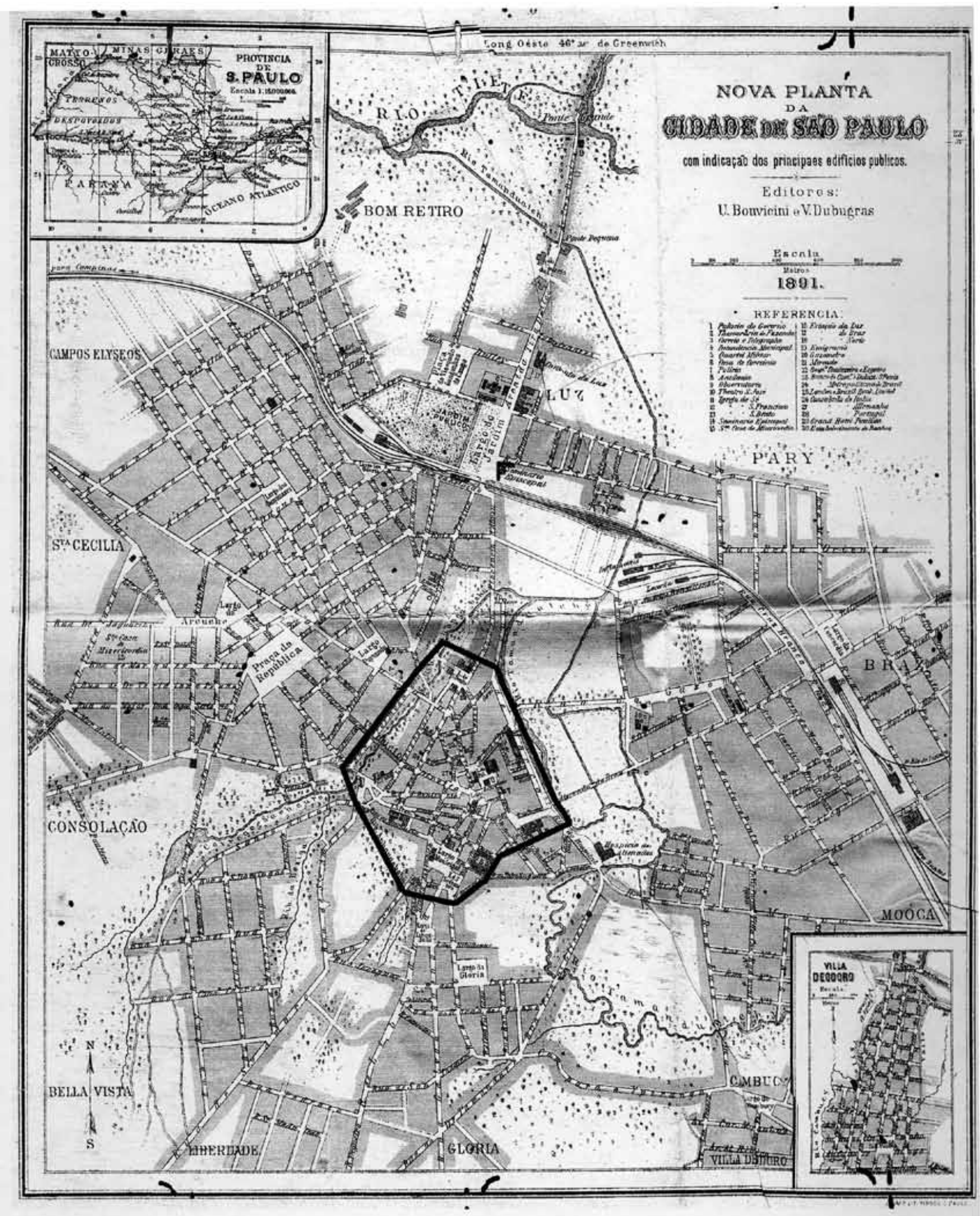

Figura 1:"Nova Planta da Cidade de São Paulo com indicação dos principaes edificios publicos - 1891 - por U. Bonvicini \& V. Dubugras" [e detalhe, circundado por um traçado em preto, com o perímetro enfocado em especial] [U. Bonvicini \& V. Dubugras/Benedito Lima de Toledo, Prestes Maia e as Origens do Urbanismo Moderno em São Paulo, São Paulo, Empresa das Artes, 1996] 
isso mesmo, trata-se de um espaço que pode exercer, como nenhum outro local da cidade, o papel de "teatro espontâneo" no qual representantes dos mais diversos grupos sociais se movimentaram e interagiram segundo regras de conduta peculiares, em momentos específicos dos Oitocentos e do início dos Novecentos.

Quanto ao período histórico no âmbito do qual me movimentei, também ele foi definido tendo como base a civilidade de que o transeunte é protagonista. Um evento que incidiu diretamente sobre a maneira de os indivíduos se movimentarem em Sáo Paulo foi a chegada da ferrovia (1865-1867). Os primeiros trilhos instalados foram a materialização física mais acabada do princípio da circulação de tudo e de todos, indo e vindo da capital. Por isso os meados da década de 1860 constituem um marco instigante de periodização, que permite avaliar como regras de civilidade vigentes nas ruas antes da implantaçáo da ferrovia se alteraram na seqüência.

Mas o quanto antes dos anos de 1860 iniciei a análise e em relação a que momento histórico a encerrei? Como a idéia era acompanhar o impacto da modernidade no plano dos comportamentos corporais e das interações nas ruas de São Paulo no século XIX, o contexto social e cultural que envolve a chamada "abertura dos portos", em 1808, ofereceu uma referência inicial interessante. $\mathrm{E}$ isso não somente porque o evento representa, em termos simbólicos e históricos, um certo prenúncio involuntário de processos históricos ligados à modernidade que agitaram, sobretudo a partir da segunda metade do século XIX, recônditos interioranos como São Paulo numa colônia cujo povoamento, ao longo de três séculos, fora principalmente litorâneo. Mas também porque foi no bojo das negociaçóes que desembocaram na decisão política de abrir os portos às "naçôes amigas" que chegou em São Paulo o viajante inglês John Mawe (1764-1829). Foi ele um dos primeiros autorizados a embrenhar-se pelos sertôes da então colônia, como resultado do favorecimento com o qual a Inglaterra pôde contar por ter viabilizado política e logisticamente a fuga da família real portuguesa $\mathrm{da}$ Corte, durante as guerras napoleônicas. O autor produziu uma documentaçáo de singular riqueza (Mawe 1812) no que diz respeito a indícios sobre sua maneira de movimentarse e de interagir com terceiros nas ruas de São Paulo entre finais de 1807 e o início de 1808. Por suas características, o relato forneceu um ponto de partida metodológico apropriado para a apreensão analítica de transeuntes na documentação. Relevante passou a ser buscar nas fontes referências aos comportamentos corporais e interaçóes dos próprios autores ou dos tipos humanos a eles correspondentes - no caso de Mawe, viajantes - nas ruas centrais da cidade.

Se o primeiro intervalo temporal contemplado perpassou grosso modo os primeiros sessenta anos do século, o segundo foi do início da década de 1880 a 1917 . É de 1882 o relato de viagem do carioca Firmo de Albuquerque Diniz (?-?) sobre a São Paulo na qual vivera, como estudante de Direito, trinta anos antes (Diniz [1882] 1978). O texto foi relevante para mim por ser o mais antigo que conheço que, produzido por um viajante brasileiro, aborda as andanças desse indivíduo pelas ruas da cidade. A novidade histórica que as memórias de Mawe representam para o primeiro intervalo temporal aqui contemplado, as notas de viagem de Diniz representam para o segundo.

O limite da investigação foi julho de 1917 , quando uma revista paulistana, $A$ Cigarra, publicou uma reportagem fotográfica pioneira sobre um cortejo fúnebre que alterou os destinos da primeira grande greve geral que estava em curso na cidade em julho daquele ano. Foi uma manifestação social que envolveu a presença maciça e politicamente determinante de mais 
de dez mil indivíduos, em boa parte, operários pouco remediados, nas ruas centrais no dia 12 de julho. Por ali conduziram em procissáo o caixão com o corpo do sapateiro espanhol José Ineguez Martinez (1896-1917), morto em confrontos com a polícia, durante a greve geral desencadeada na cidade de quase $500 \mathrm{mil}$ habitantes alguns dias antes. A publicação da série de fotografias sobre o evento expressa, em imagens, a consolidação, nas ruas de São Paulo, de duas personagens que, ao mesmo tempo em que produtos do passado, apontam para a possibilidade histórica de regras de civilidade bem diferentes ali a partir de então, na cidade. Por um lado, consagra-se o transeunte que, além de fotógrafo, é repórter: o repórter jornalístico. Por outro lado, o fotógrafo foi responsável por eternizar, em imagens, uma multidão constituída em instrumento político moderno passível de ser difundido pelo veículo de representação também moderno que é a fotografia publicada em revistas.

Explicitados esses aspectos, há como reiterar sob um novo ângulo a relevância da mediação da perspectiva etnográfica na seleção da documentaçáo. Em busca do "diálogo para valer" com os indivíduos que, em movimentação pelas ruas centrais paulistanas, se encontravam, sem saber, imersos no processo histórico de virem a ser transeuntes, foi fundamental concentrar-se em fontes históricas cujos autores discorressem direta ou indiretamente sobre $a$ sua própria maneira de deslocar-se fisicamente e de interagir socialmente nas ruas centrais da cidade ao longo dos dois intervalos em foco.

Evidentemente inexistem documentos referidos às vivências de um único indivíduo nas ruas por mais de cem anos. Porém há, em relação às ruas centrais de São Paulo, textos e fotografias que, originados no decorrer dos primeiros sessenta anos do século XIX e do intervalo entre os anos de 1880 e 1917, têm como autores indivíduos que, nos documentos que produziram, figuram como porta-vozes de tipos humanos que integraram a sociedade paulistana nos dois períodos aqui em questáo: o "viajante" (estrangeiro ou brasileiro), o "estudante da Academia de Direito", a "mulher de elite", o "jornalista", o "fotógrafo de rua".

Foram essas personagens que me cederam involuntariamente seus "ombros" para que, por detrás deles, eu pudesse apreender as mudanças nos padróes de conduta nas ruas paulistanas do século XIX. Concebi a documentação como um conjunto de testemunhas oculares nos termos - aliás, contundentemente antropológicos - do historiador Peter Burke (2001: 183), ao refletir sobre as imagens como fonte histórica: "elas testemunham as maneiras estereotipadas e, no entanto, gradualmente cambiantes pelas quais os indivíduos ou grupos enxergam o mundo social, incluindo o mundo de sua imaginação". Sob essa perspectiva, é crucial variar os olhares, os testemunhos. Rastreei as fontes à procura de indícios dos comportamentos corporais e das interaçóes desses tipos humanos com terceiros nas ruas do primeiro intervalo de estudo, apreendendo regras de conduta singulares cujas transformaçóes acompanhei em relação ao segundo período em jogo.

Tanto textos quanto fotografias foram imprescindíveis, já que são suportes diversos de "olhares" ("gazes") também diferentes a respeito do mundo social (Idem: 126,183). Mas foram textos e fotografias precisos: documentos que tematizam essencialmente a presença dos respectivos autores nas ruas centrais da Sáo Paulo nos dois intervalos. Constituíram o corpus documental da investigação em questáo primeiramente relatos de viagem de alguns estrangeiros europeus e norte-americanos sobre as vias do centro paulistano do período. Tendo freqüentado em geral, quando na cidade, as rodas mais prestigiadas da sociedade, esses forasteiros produziram em seus textos, antes de tudo, "imagens do outro" imbuídas de inevitáveis preconceitos 
e estereótipos (Idem: 139). No entanto, há mais, quando se explora o "encontro cultural" que cada um desses textos testemunha (Idem, ibidem). Por evidenciar olhares de fora sobre a movimentação física e as interaçóes dos estrangeiros com nativos nas ruas, esse material fornece instigantes contrapontos à reflexão sobre as vivências dos próprios membros "nativos" da sociedade paulistana em relação a esse espaço.

No segundo intervalo temporal, as ruas da cidade foram eternizadas em textos de estrangeiros que não estavam mais somente de passagem. Multiplicaram-se órgáos de imprensa ligados às cada vez mais numerosas colônias de imigrantes, além de fotógrafos também adventícios (envolvidos com a produção de fotografias e de cartóes postais) que na cidade se instalaram. Por isso mesmo, em relação a esse período importaram os dados que jornais, fotografias e postais pudessem conter a respeito da movimentação corporal e as interaçóes cotidianas de alguns de seus autores nas vias centrais. Debrucei-me particularmente sobre as - cotidianas - crônicas e notícias de dois desses jornais (um italiano e um alemão), mas também sobre imagens de um fotógrafo suíço e de um italiano que pelas ruas se locomoveram com regularidade entre finais do século XIX e o início do XX. As profissóes fazem desses tipos humanos representantes das nascentes camadas médias paulistanas.

Considerei, por outro lado, toda uma documentação "nativa", por assim dizer, textos e imagens produzidos por brasileiros no período. Sáo documentos pessoais (cartas, no primeiro intervalo, e um diário, no segundo) de endinheirados estudantes da Academia de Direito paulistana, aberta em 1828; memórias de antigos estudantes da instituição também oriundos das elites - ou, no mínimo, vinculados pessoalmente a estas no momento em que escreveram os seus textos; memórias de mulheres de elite sobre o seu passado de meninas abastadas na cidade. No segundo intervalo temporal contemplado entraram em cena também os livros de viagem de alguns antigos estudantes não-paulistanos da Academia: a passagem pela cidade anos após o término do curso rendeu evocaçôes memoráveis sobre a movimentação dos próprios autores pelas ruas centrais tanto de seu passado juvenil quanto do seu presente adulto.

Mas também havia nesse período na cidade tipos humanos "nativos" que, pela profissão, podem ser associados às camadas médias de São Paulo. Foram importantes, por um lado, determinadas crônicas e notícias jornalísticas que começam a ser trazidas a público pelos nascentes jornalistas na cidade a partir de 1854, com o aparecimento do primeiro jornal paulistano que assumiu o dia-a-dia das ruas como assunto cada vez mais constante de suas páginas. Por outro lado, consegui encontrar fotografias da área central produzidas também por brasileiros, nos dois intervalos em questão. Os autores dessa documentação provavelmente também tenham tido laços com as elites. Como era muito restrito o número de alfabetizados na cidade - e, de resto, no país - , não é difícil inferir que os leitores dos jornais e mesmo os empregados ligados a esses órgãos de imprensa fossem aparentados daqueles em cujos círculos a probabilidade de letrados poderia ser maior, dependendo das condiçóes econômicas.

É certo que cada um dos documentos foi produzido a partir de lugares sociais distintos - e mesmo em tempos e espaços diversos, se levamos em conta que as memórias e, em particular, as memórias de viagem, não foram produzidas em São Paulo. Além disso, cada fonte obedece aos ditames formais dos respectivos tipos documentais a que pertence, em meio à dinâmica de sua produção. Isso para não falar de aspectos de apreensão mais difícil. Memórias de viagem, de infância e de juventude, nas cartas e diários pessoais, resultam de seleções que 
obedecem a critérios de fundo eminentemente afetivo. Já no caso das crônicas e notícias dos jornais, as seleçóes obedecem a critérios políticos e literários. Nas fotografias e cartóes postais fotográficos sobre as ruas, a seleção é de outro tipo ainda, obedecendo à natureza da própria fotografia. Combina limitaçóes técnicas, a perspectiva do fotógrafo, referida à própria inserção deste no mundo social, e a "imaginação fotográfica” que, ensejada por motivaçóes estéticas ou documentais, leva o fotógrafo a buscar desconstruir o visível (Martins 2002: 223). Esses critérios variados se transformam, em última instância, em pretextos que norteiam a escolha que os respectivos autores fazem desse ou daquele aspecto implícito à sua movimentação pelas ruas, a fim de eternizá-lo, explícita ou implicitamente, nos diversos gêneros documentais considerados. Se, nas fontes textuais, o que resulta da escolha são fragmentos mais ou menos ficcionais relativos aos "imponderáveis" implícitos às andanças dos respectivos autores pelas ruas paulistanas, nas fotografias a realidade fotografada constituída na fixidez da película retida pela moldura remete de forma imediata a fragmentos efetivos da movimentação física do fotógrafo na hora da tomada 5 .

Mediada por esses aspectos todos, a seleção de cada autor acabará por conter referências diretas ou indiretas à maneira como estes teriam se movimentado fisicamente e interagido diaa-dia nas ruas do período. Foi essa a matériaprima de minha análise. E dá-lhe perspectiva etnográfica, nesta etapa da investigaçáo trabalhada em termos teórico-metodológicos por

5. É preciso considerar a condição indicial da fotografia - ou seja, o fato de meramente afirmar, pelo ato que a funda, a existência de uma realidade (objeto, paisagem) à qual se referencia (Dubois [1990]1994: $55,88,51-2)$. Após o ato de exposição da chapa à luz, essa realidade é "imediatamente (re-)tomada, (re)inscrita nos códigos" relativos às "formas culturais da representaçẫo" (Idem: 85-6). meio de interlocução com as consideraçóes de outro historiador afinado com a antropologia: Carlo Ginzburg ([1979]1991; [1989]1989). As referências sobre a movimentação corporal e as interaçóes contidas nas fontes se insinuam através de detalhes cujo significado interpretativo se define a partir do cruzamento a que o pesquisador submete os dados contidos fontes. Desse cruzamento emerge um desencontro entre aquilo que Ginzburg chamou de "opacidades" e de "zonas privilegiadas - sinais, indícios" de uma "realidade" mais ampla ([1979]1991: 177).

Em função da experiência que tiveram das ruas paulistanas, os autores da documentação transformaram-se, após todo esse tratamento teórico-metodológico epistemologicamente informado pela etnografia, em informantes por trás de cujos "ombros" documentais pude empreender a etnografia das ruas do passado. Informantes revelados pela documentação a partir do diálogo que, pela mediação da perspectiva etnográfica, pude travar com a teoria - antropológica, sociológica, histórica ${ }^{6}$.

Há que se ressaltar, por fim, que a perspectiva etnográfica imbui também a representação literária dos resultados da investigação. De fato, concebo narrativamente o texto monográfico em questão como etnografia da civilidade que, nas ruas, foi historicamente possível para tipos humanos específicos que estavam vinculados às elites e às camadas médias paulistanas entre o início do século XIX e o início do XIX (Frehse 2004: 51-54). Assumindo como ponto de partida literário os discursos de cada uma das personagens sobre a sua maneira de se movimentar pelas vias centrais (capítulos 1 e 2) e de interagir ali (capítulo 3) nas primeiras seis décadas do século, a primeira parte da monografia avança, a partir dos indícios sobre os comportamentos corporais, para as regras envolvidas na movimentaçáo corporal de via-

6. Sobre a pertinência de falar em informantes "quando o campo é o arquivo”, cf. Frehse (2005b: 131-156). 
jantes, de estudantes de Direito, de mulheres de elite, de jornalistas e fotógrafos ali naquele período (capítulos 1 e 2). Ancorado nesses dados, o texto parte em direçáo a pistas sobre os padróes de conduta das interaçóes nas ruas nesse período (capítulo 3). Após um Intermédio que evoca as transformações socioeconômicas, demográficas, urbanísticas, tecnológicas e político-administrativas pelas quais as ruas centrais de São Paulo passaram no intervalo entre os anos de 1860 e 1880 , entra em cena a segunda parte do estudo. É então a vez respectivamente dos discursos, indícios e das regras referidas às ruas do centro paulistano no intervalo entre 1880 e 1917 (capítulos 5, 6 e 7).

A referência teórica que orientou a estrutura argumentativa, na qual cada parte se constitui a partir dos indícios sobre os comportamentos corporais, a fim de aprofundar verticalmente, na seqüência (respectivamente capítulos 3 e 7), as regras envolvidas nas interaçóes em meio a esses comportamentos, foi a premissa geertziana de que ao antropólogo cabe concentrar-se na "hierarquia estratificada de estruturas significativas" ([1973]2000: 7). No caso, trata-se de uma hierarquia de significados que, apreensíveis através do cruzamento de dados das diferentes fontes, dizem respeito a regras que, por sua vez, perpassam os comportamentos corporais e, pela mediação destes, as interaçóes em questão. Mas lanço mão da noção de etnografia para caracterizar a monografia tendo em conta que a estrutura de cada uma de suas partes tem um caráter densamente descritivo: iniciando-se na descrição dos indícios sobre a movimentação física nas ruas, a argumentação passa para as regras significativas que esses indícios sugerem para comportamentos corporais e interaçóes. Já o Intermédio é a mediação que dá sentido a essa densidade, de conteúdos socioculturais e históricos diferentes em cada período, por mais que a lógica cultural implícita às regras, a etiqueta, permaneça inalterada.
Etnografia, mas também perspectiva etnográfica, já que o enfoque sobre as movimentaçôes corporais e nas interações dos diferentes transeuntes pelas ruas em cada momento é uma estratégia literária que visa aproximar cognitivamente o leitor tanto daquelas vias que se torna quase inevitável que ele seja levado a estranhar as suas próprias, deste início de século XXI. Se estas são ruas paulistanas, quantas diferenças... Mas também, tantas semelhanças...

\section{Em meio a limitaçóes, rendimentos de cunho teórico-metodológico e li- terário}

Escaparia aos intuitos deste artigo apresentar os resultados interpretativos detalhados na e através da etnografia das ruas do passado que constitui a monografia em questão (cf. nesse sentido Frehse 2004). Mais vale apontar o que o exercício de estranhamento aqui realizado revela sobre as potencialidades da etnografia para a abordagem antropológica justamente das ruas paulistanas oitocentistas. São potencialidades que se apresentam em meio às inevitáveis limitaçóes do recurso quando o assunto são problemáticas referidas a um tempo histórico que não é aquele em que vive e pesquisa o antropólogo.

As limitações são óbvias quando se assume como parâmetro a concepçáo clássica de etnografia vigente na antropologia. Não há como ter contato físico com os nativos que se estuda; não há como "conversar com eles" (Geertz, [1973]2000: 13), portanto. Ademais, se, como diz Geertz, os dados do antropólogo são sempre construçóes das construçôes dos outros (Idem: 9), as construçóes, no caso de estudos antropológicos de temáticas históricas, se fazem com base apenas em indícios das construçôes dos outros.

Entretanto, penso que o exercício de estranhamento aqui realizado contribui para atestar que as limitações não são suficientes para de- 
mover o antropólogo do empreendimento, se o que ele visa é afirmar, a partir dos referenciais da disciplina, algo sobre a sociedade em questão. Existe uma perspectiva etnográfica que o acompanha mesmo quando ele se defronta com modos de viver, de pensar e de se relacionar socialmente que não lhe são contemporâneos. Essa perspectiva medeia a construção teórico-metodológica da investigação, perpassa a coleta, análise e interpretaçáo dos dados, a redação dos resultados.

Se contemplada sob esse prisma, a etnografia é, por um lado, prenhe de rendimentos de cunho teórico-metodológico para a abordagem das ruas do passado. Ela abre espaço para que se problematize antropologicamente, lançando mão do norte epistemológico que é o "diálogo para valer", essa seara muito específica da vida social que é a vida de todo dia. Trata-se de um ponto de reparo passível de descortinar os dilemas culturais e históricos envolvidos nos fatos aparentemente menores do dia-a-dia. Sobretudo quando o assunto são a cidade e a modernidade, temáticas tão caras às chamadas "sociedades complexas", a perspectiva etnográfica incentiva o pesquisador a estranhar essa seara, influenciada de forma tão contundente por esse modo de vida historicamente peculiar que é o cotidiano. Tal ponto de vista permite trazer à tona, em meio ao vigor do processo histórico de difusão da modernidade pelos quatro cantos do mundo, as ressignificaçóes peculiares deste, dependendo do contexto sócio-histórico e cultural em questão.

Paralelamente há potencialidades literárias na etnografia. Balizando a elaboração de textos fortemente marcados por fórmulas narrativas que visam conduzir o leitor pela "hierarquia de estruturas significativas" que envolvem as práticas culturais, a perspectiva etnográfica implícita à etnografia acaba por incentivar a reflexividade do leitor, ao mesmo tempo tão próximo e táo distante do contexto descrito densamente na etnografia.

Expostos esses rendimentos, seria possível inverter a questáo inicial deste texto para refletir sobre a potencialidade que uma análise das ruas do passado pode ter para a antropologia. Se não é o caso aqui de delongar-se nesse sentido, ciente de que essa tentativa é, ela mesma, pretexto para um outro artigo, reconheço que, por meio do empreendimento aqui tematizado, fui levada a ponderar sobre mediaçóes teórico-metodológicas que, por mais que perpassem também as etnografias realizadas no chamado "presente etnográfico", nestas freqüentemente passam desapercebidas, ou não são explicitamente problematizadas em função de uma confiança talvez excessiva do antropólogo nas virtudes dos insights "em campo". Refiro-me especialmente à definição da questáo teórica a ser analisada, mas também à construção teórica de uma referência metodológica para abordar essa questão, o que acarreta a elaboração de etnografias bem específicas, através de informantes singulares, que são construçóes também teóricas, mais do que resultados exclusivos do contato empírico com o campo. Isso para não falar da relevância da chamada "crítica da fonte", tão conhecida dos historiadores, para o processo de coleta, análise e interpretação de dados etnográficos.

Já do ponto de vista teórico, foi possível reconhecer a perturbadora da historicidade de longa duração que impregna práticas culturais como a civilidade. Explorando a hierarquia de estruturas simbólicas, deparei-me com regras de conduta com conteúdos diversificados em momentos históricos distintos; mas a lógica simbólica que os envolve tem uma historicidade que faz reaparecerem em plena rua republicana e pós-escravista regras de conduta cerimoniais do período escravista. Em face dessa constataçáo, fica para a antropologia a seguinte questáo: Há como compreender os significados dos comportamentos sem recorrer à história?

Em meio a suas limitaçóes e possibilidades, 
a etnografia das ruas do passado, mesmo que ofereça uma história da sociedade paulistana oitocentista e do início do século XX, não deixa de ser antropológica. Mas uma antropologia que parte de um pressuposto específico: o de que esta sociedade - se não toda - não pode ser pensada sem que se incorpore à reflexão sobre ela suas especificidades na maneira de perceber, viver, conceber a passagem do tempo.

\section{Potentialities of an ethnography of streets of the past}

abstract Based on the theoretical and methodological background of my doctoral thesis in historical anthropology (Frehse 2004), this paper aims at reflecting on ethnography's potentialities for the anthropological study of historical issues. Its specific purpose is exploring the potentialities of an ethnography of the São Paulo central streets between the beginning of the $19^{\text {th }}$ and the beginning of the $20^{\text {th }}$ century. In order to emphasize these potentialities, the discussion follows in two steps. First I theoretically develop the thesis that ethnography may also be present in anthropological studies of historical issues as it is permeated with a specific epistemological perspective: the ethnographic perspective. With the aim of testifying to the consistency of the argument, I evaluate the presence of ethnography in my own doctoral study. It will then be possible to highlight that ethnographic perspective has theoretical, methodological and literary potentialities notwithstanding ethnography's unavoidable limitations for the anthropological study of historical issues.

keywords Historical Anthropology. Ethnography. Epistemology. Ethnographic perspective. Ethnography and everyday life.

\section{Referências bibliográficas}

ANPOCS. 2001. Seminário temático "A antropologia e seus métodos: o arquivo, o campo, os problemas".
Caxambu: XXV Encontro Anual da ANPOCS. Disquete.

BLOCH, Maurice. 1977. "The past and the present in the present". Man, 12: 278-92.

BURKE, Peter. 2001. Eyewitnessing. The uses of images as historical evidence. Ithaca: Cornell University Press.

CLIFFORD, James. [1983]. "Sobre a autoridade etnográfica”. Trad. Patrícia Farias. Rev. Técn. José Reginaldo Santos Gonçalves. In J. R. S. Gonçalves (org.), James Clifford. A experiência etnográfica. Antropologia e literatura no século XX. Rio de Janeiro: Editora da UFRJ, 2002, pp. 17-62.

; MARCUS, George. (eds.). 1986. Writing culture. The poetics and politics of ethnography. Berkeley/Los Angeles/London: University of California Press.

DAMATTA, Roberto. [1974]. "O ofício do etnólogo ou como ter anthropological blues". In E. Nunes (org.), A aventura sociológica. Rio de Janeiro: Zahar, 1978, pp. 23-35.

DINIZ, Firmo de Albuquerque (Junius). [1882]. Notas de viagem. São Paulo: Governo do Estado de São Paulo, 1978.

DUBOIS, Philippe. [1990]. O ato fotográfico e outros ensaios. Trad. Marina Appenzeller. Campinas: Papirus, 1994.

ELIAS, Norbert. [1939]. Über den Prozess der Zivilisation. Soziogenetische und psychogenetische Untersuchungen. 2 vols. Frankfurt am Main: Suhrkamp, 1993.

ESTUDOS HISTÓRICOS. 2005. Antropologia e arquivos, 36/2.

FREHSE, Fraya. 1999. Entre o passado e o presente, entre a casa e a rua: tempos e espaços na cidade de Sáo Paulo de fins do Império. Dissertação de Mestrado em Antropologia Social. São Paulo: Faculdade de Filosofia, Letras e Ciências Humanas - Universidade de São Paulo.

2004. Vir a ser transeunte. Civilidade e modernidade nas ruas da cidade de São Paulo (entre o início do século XIX e o início do século XX). Tese de Doutorado em Antropologia Social. São Paulo: Faculdade de Filosofia, Letras e Ciências Humanas - Universidade de São Paulo.

2005a. O tempo das ruas na Sáo Paulo de fins do Império. São Paulo: Edusp.

2005b. "Os informantes que jornais e fotografias revelam: para uma etnografia da civilidade nas ruas do passado". Estudos Históricos, 36: 131-156.

GAUNT, David. 1982. Memoir on history and anthropology. Stockholm: The Swedish Research Councils/Publishing House.

GARFINKEL, Harold. [1967]. Studies in ethnomethodology. Cambridge: Polity Press, 1984.

GEERTZ, Clifford. [1980] Negara. O estado teatro no sé- 
culo XIX. Trad. Miguel Vale de Almeida, $1^{\mathrm{a}}$ ed. Lisboa: Difel/Bertrand Brasil, 1991.

[1973]. The interpretation of cultures. Selected essays. New York: Basic Books, 2000.

[1983]. Local knowledge. Further essays in interpretive anthropology. New York: Basic Books, 2000.

1988. Works and Lives. The anthropologist as author. Stanford: Stanford University Press.

GINZBURG, Carlo. [1979]. "Sinais. Raízes de um paradigma indiciário”. In C. Ginzburg, Mitos, emblemas e sinais. Morfologia e história. São Paulo: Companhia das Letras, 1991, pp. 143-189.

1989. "O inquisidor como antropólogo". In

C. Ginzburg, A micro-história. Lisboa: Bertrand, pp. 203-214.

GOFFMAN, Erving. [1956]. "The nature of deference and demeanor". In E. Goffman, Interactional ritual. Essays on face-to-face behavior. Garden City: Anchor Books, 1967, pp. 47-95.

[1959]. A representação do eu na vida cotidiana. Trad. Maria Célia Santos Raposo. Petrópolis: Vozes, 1995.

1967. Interaction ritual. Essays on face-to-face behavior. Garden City: Anchor Books.

GOLDMAN, Márcio. 2001. "Do ponto de vista nãonativo: sobre a incompreensão antropológica ou os tambores dos mortos e os tambores dos vivos". Comunicação apresentada no seminário temático "A antropologia e seus métodos: o arquivo, o campo, os problemas", XXV Encontro Anual da ANPOCS, Caxambu. Mimeo.

LEFEBVRE, Henri. 1958, 1961, 1981. Critique de la vie quotidienne. 3 vols. Paris: L'Arche Éditeur.

1966. La sociologie de Marx. Paris: Puf.

. [1968]. La vida cotidiana en el mundo moderno.

Trad. Alberto Escudero. Madrid: Alianza Editorial, 1972.

1970. La revolution urbaine. Paris: Gallimard.

1992. Élements de rythmanalyse. Introduction à la connaissance des rythmes. Paris, Syllepse.

LÉVI-STRAUSS, Claude. [1950]. "Introduction à l'oeuvre de Marcel Mauss". In M. Mauss, Sociologie et anthropologie. Paris: PUF, 1997, pp. ix-li.

. [1958]. Antropologia estrutural. Trad. Chaim Samuel Katz e Eginaldo Pires. Rio de Janeiro: Tempo Brasileiro, 1970.

[1960]. Antropologia estrutural dois. Trad. Maria do Carmo Pandolfo et alii. Rio de Janeiro: Tempo Brasileiro, 1972.

MAGNANI, José Guilherme Cantor. 2002. "De perto e de dentro: Notas para uma etnografia urbana”. Revista Brasileira de Ciências Sociais, 17 (49): 11-29.

MALINOWSKI, Bronislaw. [1922]. Argonautas do Pacífico Ocidental: Um relato do empreendimento e da aventura dos nativos nos arquipélagos da Nova Guiné, Melanésia. Trad. Anton P. Carr e Lígia Aparecida Cardieri Mendonça. Rev. Técn. Eunice Ribeiro Durham. São Paulo: Abril Cultural, 1978.

MARCUS, George E.; CUSHMAN, Dick. 1982. "Ethnographies as texts". Annual Revue of Anthropology, 11:25-69.

MARTINS, José de Souza. [1998]. "O senso comum e a vida cotidiana”. In J. de Souza Martins, A sociabilidade do homem simples. São Paulo: Hucitec, 2000, pp. 5-64.

2002. "A imagem incomum: a fotografia dos atos de fé no Brasil". Estudos Avançados, 45: 223-260.

MAWE, John. 1812. Travels in the interior of Brazil. Particularly in the gold and diamond districts of that country. By authority of the Prince Regent of Portugal. London: Longman, Hurst, Rees, Orme and Brown, Paternoster-Row-Strahan and Preston.

MAUSS, Marcel. [1936]. «Les techniques du corps». In M. Mauss, Sociologie et anthropologie. Paris: Quadrige/ Puf, 1997, pp. 363-386.

MCCALLUM, Cecília. 2001. "O saber antropológico e a totalidade nos fatos sociais". Comunicação apresentada no seminário temático "A antropologia e seus métodos: o arquivo, o campo, os problemas", XXV Encontro Anual da ANPOCS, Caxambu. Mimeo (citado com permissão da autora em e-mail de 29 de novembro de 2006).

PEIRANO, Mariza. 1995. A favor da etnografia. Rio de Janeiro: Relume Dumará.

2006. A teoria vivida e outros ensaios de antropologia. Rio de Janeiro: Jorge Zahar Editor.

PONS, Alan. 1992. "Sur la notion de civilité". In A. Montandon (org.), Etiquette e politesse. Clermont-Ferrand: Association des Publications de la Faculté des Lettres et Sciences Humaines de Clermont-Ferrand, pp. 19-30.

REVEL, Jacques. [1986]. "Os usos da civilidade". In P. Ariès; R. Chartier (orgs.), História da vida privada [Vol. 3: Da Renascença ao Século das Luzes]. Trad. Hildegard Feist. São Paulo: Companhia das Letras, 1991, pp. 169-209.

ROWLAND, Robert. 1987. Antropologia, história e diferença. Alguns aspectos. Lisboa: Ediçōes Afrontamento.

SAHLINS, Marshall. 1981. Historical metaphors and mythical realities. Ann Arbor: The University of Michigan Press.

. [1985]. Ilhas de história. Trad. Barbara Sette. 
Rev. Técn. Márcia Bandeira de Mello Leite. Rio de Janeiro: Zahar, 1994.

SCHÜTZ, Alfred. [1970]. Fenomenologia e relaçóes sociais. (org. Helmut R. Wagner), tradução de Ângela Melin. Rio de Janeiro: Zahar, 1979.

SIMMEL, Georg. [1903]. "A metrópole e a vida mental”. Trad. Sérgio Marques dos Reis. In O. Velho (org.), $O$
Fenômeno Urbano. Rio de Janeiro: Zahar, 1967, pp. 13-23.

VIVEIROS DE CASTRO, Eduardo. [1998]. "Entrevista com Eduardo Viveiros de Castro”. In E. Viveiros de Castro, A inconstância da alma selvagem. E outros ensaios de antropologia. São Paulo: Cosac \& Naify, 2002, pp. 475-492.

\section{autor Fraya Frehse}

Professora do Departamento de Sociologia / USP

Doutora em Antropologia Social / USP

Pesquisadora NAU / USP

Editou a Cadernos de Campo $\mathrm{n}^{\text {os }}$ 5/6 a 9

Recebido em 10/01/2007

Aceito para publicação em 31/01/2007 